\title{
A Randomized Controlled Trial Study on Hypertension Reduction Based on Disease Control Priorities to Manage High Blood Pressure
}

\section{Subhana Akber Khan ( $\nabla$ subhanaakber@gmail.com )}

Health Services Academy https://orcid.org/0000-0002-9538-4320

\section{Shahzad Ali Khan}

Health Services Academy

Assad Hafeez

Health Services Academy

Arif Zaka

Armed Forces Institute of Cardiology and National Institute of Heart Diseases

\section{Research}

Keywords: Hypertension, Hypertensive Patients, Disease Control Priorities, Non-Communicable Diseases, Pakistan

Posted Date: August 19th, 2021

DOl: https://doi.org/10.21203/rs.3.rs-704550/v1

License: (9) This work is licensed under a Creative Commons Attribution 4.0 International License. Read Full License 


\section{Abstract}

\section{Background}

One of the global targets for non-communicable diseases is to reduce the prevalence of hypertension by $25 \%$ by year 2025. In Pakistan, prevalence of hypertension is reported to be $24.9 \%$ among males and in females the prevalence is $24.7 \%$. The purpose of this study was to test the deliverability of a multicomponent based intervention for reduction of high blood pressure to recommended $140 / 90 \mathrm{~mm}$ of $\mathrm{Hg}$ and to test its effectiveness in control of hypertension among hypertensive patients.

\section{Methods}

Using a randomized controlled trial, double blinded study design, the intervention was pilot-tested for its appropriateness for implementation in hospital. The intervention was given to hypertensive patients in the intervention group. A total of 240 participants were screened and recruited into the trial after obtaining an informed consent. An ethical approval was sought from Health Services Academy. Data was collected from December 2019 to March 2020. All the data was entered and analyzed uing SPSS version 21.

Results

Implementation of a multi-component intervention to test DCP3 based strategies for management and control of hypertension in a hospital setting during three months yielded $-23.9 \mathrm{~mm} \mathrm{Hg}$ of systolic blood pressure reduction ( $95 \%$ confidence interval, $p \leq 0.005$ ). A significant reduction in the blood pressure to recommended target in intervention group was achieved in 6th, 8th and 12th week. As compared to patients in usual care group, improved health outcomes were achieved for diet control, reduction in salt intake and an increased physical exercise among hypertensive patients. Regular follow up and strict adherence to prescribed medicines was observed in both groups.

\section{Conclusion}

Study findings concluded that the multicomponent intervention particlulary use of low salt and lifestyle modifications is effective in hypertension reduction. Involving family members of the patient was an essential component of non-pharmacologocal treatment which was found to be beneficial for management and control of hypertension.

Trial registration: The study was registered in clinicaltrials.gov number NCT04336631 dated April 07, 2020.

\section{Contributions To The Literature}

- This study contributes to testing of an intervention related to hypertension management and control which is based on third edition of disease control priorities. 
- A randomized controlled trial study was conducted in which a multi-component intervention for hypertension was tested for its acceptability and feasibility which was implemented in hospital setting.

- DCP3 based intervention for hypertension aimed to deliver pharmacological treatment, nonpharmacologocal treatment, behavioural counselling and lifestyle modifications to hypertensive patients which produced significant reduction in high blood pressure of patients in the intervention group as compared to usual care group.

- Locally, a limited evidence is available of providing comprehensive health care to hypertensive patients therefore an intervention comprising of multiple components of preventive health services was linked to improved health outcomes among patients.

\section{Introduction}

Hypertension is a common condition in which the blood flows at a higher pressure than in normal state through arteries or veins or blood vessels (1-3). Recent guidelines of ICD-11 categorizes blood pressure into four levels. In a clinical setting, an average of blood pressure measurements is usually taken by healthcare providers. These categories are labeled as normal blood pressure, elevated blood pressure, stage 1 hypertension and stage 2 hypertension (4). It can be divided into primary or essential hypertension which occurs in $95 \%$ of cases whereas; secondary hypertension occurs in $5 \%$ of the cases. Hypertension is associated with cardiovascular diseases which results in significant morbidity and mortality worldwide. Hypertension for a long-term or chronic elevation of blood pressure causes organ damage, eventually (5). There are several possible and interrelated factors that are involved in development of hypertension. Intake of sodium/salt (NACl) in diet, insulin resistance, genetics, and obesity are some of the non-modifiable risk factors for hypertension. Whereas; renin-angiotensinaldosterone system, cardiac output, peripheral resistance is also implicated in hypertension development. Although, the interaction between these systems along with other factors including sodium, hormones and circulating volume of blood that all act in the development of hypertension.

Approximately, more than 7 million deaths are accounted due to increased pressure of blood which reasons $12.8 \%$ of all causes of deaths in the world (6). First incidence of having an event of cardiovascular diseases is $10 \%$ among male hypertensive patients whereas, it is less than $5 \%$ among female hypertensive patients over a period of ten years (5). Worldwide, the prevalence of increased blood pressure among men and women of age 18 years and above was $24 \%$ and $20 \%$, as respectively. In Pakistan, the prevalence of hypertension is reported to be $24.9 \%$ in males and in females the prevalence is reported to be $24.7 \%$. Among adults of age above 18 years, one in four is reported to be hypertensive along with smoking in Pakistan. Evidence also suggests that hypertension is more common among males than in females. Hypertensive patients with arterial hypertension have either increased systemic vascular resistance or increased cardiac output or both. However; if patients suffering from hypertension are stratified in terms of younger and older age groups then the predominant cause among young people is an increase in cardiac output on the contrary; in older age people it is often the systemic vascular 
resistance or an increased vascular stiffness causing vasoconstriction thus resulting in an increased blood pressure. This elucidates that age is a strong predictor of the risk of cardiovascular complications and an increase in responsiveness to stressful stimuli. Regulation of blood requires that the pressure of blood against walls of vessels is not overloaded which results in left ventricular hypertrophy and coronary artery diseases. The risk of severity of high blood pressure is determined by progression of the disease but it is independent of the morbidity that is caused due to increase in blood pressure throughout its range of spectrum. As compared to normotensive individuals, patients with uncontrolled hypertension are most likely develop complications of myocardial ischemia, myocardial infarction, stroke, thrombosis, cardiac congestion which eventually leads to heart failure along with renal failure in some of the cases which is common if high blood pressure is left untreated (5).

In all populations, high risk group individuals having a family history of cardiovascular diseases or increased risk of cardiovascular morbidity, the risk of increased weight or obesity, non-sedentary life style, dietary pattern along with presence of other non-modifiable risk factors can affect the range of clinical outcomes along with pharmacological treatment. Prevalence of hypertension is increasing even when pharmacological treatment and recommended drug therapy is administered to the patients. Preventive measures such as dietary changes including a sodium restrictive diet and life style modifications including reduction in the weight along with regular physical exercise are found to be effective. Adherence to treatment prescribed by physicians can help in controlling raised blood pressure among hypertensive patients $(5,7)$. Globally, a high prevalence of hypertensive patients can be attributed to an increase in population growth and aging. However; hypertension is $40 \%$ prevalent in low and middle income countries than in high income countries which is approximately $35 \%$ of their total population. More men tend to have raised blood pressure as compared to women in all WHO regions (8-10). Worldwide, hypertension prevails due to increased longevity and presence of contributing risk factors (11). The aim of this study is to reduce systolic blood pressure (SBP) to recommended level of $\geq 140 \mathrm{mmHg}$ among hypertensive patients who are registered in this study. Further, to test effectiveness of DCP3 based multicomponent intervention in reducing systolic blood pressure among hypertensive patients after three months of delivering the intervention (Table 1). The primary hypothesis was that hypertensive patients receiving DCP3 based multicomponent intervention will have a greater reduction in systolic blood pressure after three months as compared to patients in the usual care group who will be receiving usual medical care. This study was carried out in accordance with CONSORT guidelines (12).

\section{Methods}

\section{Inclusion and Exclusion Criteria}

The study included Pakistani nationals both male and female of age 18 years and above who were either newly diagnosed or known hypertensive patients having blood pressure of greater than $\geq 140 \mathrm{mmHg}$ on current treatment or otherwise. Hypertensive patients with life-threatening co-morbidities were excluded such as those suffering from cardiac ailments (angina or transient ischemic attack (TIA), angiographically proven coronary disease, peripheral or cerebral vascular disease, pulmonary 
hypertension, having history of myocardial infarction, stroke or angioplasty / PCl or stent or high-risk conditions.

\section{Operational Definitions}

High blood pressure is defined according to International Classification of Diseases $10^{\text {th }}$ revision (ICD-10) (13). According to which hypertension was classified as systolic blood pressure of greater than $\geq 140$ $\mathrm{mmHg}$ and diastolic blood pressure of $\geq 90 \mathrm{mmHg}$. Blood pressure control is considered when the systolic BP is less than or equal to $140 \mathrm{~mm} \mathrm{Hg}$ and the diastolic BP is less than or equal to $90 \mathrm{~mm}$ of $\mathrm{Hg}$ (37). For testing DCP3 based intervention and to enable delivery of intervention among hypertensive patients (14), the following constructs were adapted according to which intervention was modified: a) Acceptability whichreferred to the extent that stakeholders involved in qualitative research phase agreed on the use of intervention for treating hypertensive patients which included the aspect of behavioral counseling b) Appropriateness is considered as a measure of relevance of a health intervention to the disease under study and it's perceived use among hypertensive patients $\mathbf{c}$ ) Feasibility: The trilability of the intervention to be tested with relevance to hypertensive patients at the hospital setting. The modified intervention was pilot-tested and was externally validated by experts and was then implemented at the hospital.

\section{Study Design \& Study Population}

A randomized controlled trial, double-blinded study design was used (Figure 1) to conduct this study at a single study site in which participants and physicians cannot predicted if patient will be given the intervention. The clinical trial was registered at ClinicalTrials.gov number, NCT04336631. The study was conducted at Armed Forces Institute of Cardiology \& National Institute of Heart Diseases (AFIC/NIHD) in Rawalpindi city of Punjab province of Pakistan (15). The medical team of the hospital mainly composed of doctors, cardiologists, psychologist, nurses and pharmacists along with general duty staff along with research assistants who cooperated in the research data collection at the hospital. Hypertensive patients were enrolled in the trial from $1^{\text {st }}$ of November 2019 till $30^{\text {th }}$ of December 2019 and a registry of all study participants was created after which data collection was continued and was completed in March 2020. Patients were invited to participate in this study and were included only after obtaining their verbal and written consent for participation. No invasive procedure entailed the study and no sensitive information was collected. They were informed about the study purpose and were encouraged to participate in the research without having any direct benefits or monetary gains.

\section{Sampling of Study Population}

First 1000 hypertensive patients or patients with uncontrolled hypertension were selected through convenience-based sampling technique then after achieving stratification, a total of 240 patients were randomly allocated into intervention group and non-intervention group. Sample size was calculated using a two-tailed alpha level of $p=0.05$ and power of 0.80 including a non-response rate of $10 \%$. 


\section{Ethics Approval and Consent to Participate}

The study was carried out in accordance to research protocol and guidelines developed to conduct this study which involved human subjects(16). The study protocol was approved by Health Services Academy Islamabad vide letter no. 01-07/2017/PhD dated: 8th November, 2019. The materials and methods employed to conduct this study were divided into two phases. The qualitative reserach phase entailed testing DCP3 based intervention for hypertension control among hypertensive patients in the study (16). After completion of initial phase the implementing phase was carried as per the established clinical guideliens (17). The implementation phase consisted of delievering the multicomponent intervention adapted in local context among hypertensive patients.

\section{Randomization and Intervention}

For the intervention phase, hypertensive patients were screened and recruited into the trial on basis of predefined selection criteria. Hypertensive patients were randomized to intervention group (IG) or the usual care group (non-intervention group) in a 1:1 ratio. Participants were randomized and were stratified according to their gender and age groups of less than $\leq 30$ years and more than $\geq 30$ years of age (Figure 1). All study participants were approached during clinical hours and were followed up at outpatient department (OPD) of the hospital. Initial check-up of patients was carried at emergency department (ER) along with a senior physician. After physical examination of patients they were referred for blood pressure measurement and medical treatment. In emergency cases, the family members were also involved. In emergency situation, particpants were allowed to withdraw from the study only after approval from the researcher. The patients were registered into study with their CNIC / Medical Record (MR.No.) number. Approximately, 240 systematically selected hypertensive patients with uncontrolled hypertension or with systolic BP of $\geq 140 \mathrm{mmHg}$ were invited for participation for pilot-testing. They were included in the study, and their systolic and diastolic blood pressure were measured. They were assessed for their medical history and current pharmacological therapy including necessary diagnostics tests. Randomization was achieved using random number which was generated through Microsoft excel and every $9^{\text {th }}$ patient was selected in the OPD of hospital by the researcher. The intervention was only administered to patients who were randomized in the intervention group. The intervention was implemented among 240 hypertensive patients with 120 patients in intervention and usual care group. Baseline data was gathered at initial point of contact in which each patient was interviewed using a face to face interview approach. They were provided guidance for follow up at every two weeks for BP measurements, pharmacological treatment and counselling. At every follow up, they were referred to consulting physician or medical officer for their routine medical care and physical examination. The blood pressure and weight measurements were assessed at each follow up visit. Following routine medical care, patients in intervention group were provided counseling on diet, physical exercise, life style modifications. In pilot phase of the study, key messages were then formulated on basis of available evidence and qualitative research findings upon which the intervention was further modified. It was then tested for its timing and mode of delivery in OPD setting. Patients in usual care arm received routine medical care for hypertension. Patients receiving the intervention and patients in usual care arm were 
followed up at two weeks interval for their BP measurements. Each patient served as the unit of randomization and was assigned to either intervention or usual care group of the trial. Randomization was ensured by blinding subjects using an envelope method.

\section{Trial Measurements}

Hypertensive patients were allocated to intervention group and usual care group in a 1:1 ratio. Baseline characteristics of all study participants were recorded. The height of patients was measured using a stadiometer which was fixed by a wall in the OPD. Similarly, weight was measured using a weighing machine and body mass index (BMI) of each patient was recorded. Initially, blood pressure of each patient was measured after every 5 minutes and every patient was asked to sit in a relaxed position. It was measured using the left arm at 45 degrees for blood pressure check-up for which brachial artery was palpated. Three readings of blood pressure measurements were taken and an average of the readings were recorded. Patients were also instructed to report any adverse event to the physician and researcher. To reduce contamination, data for the study was collected at a point distant to physician's room in the OPD department. Regular data sheets were checked for any missing information and all the data was recorded and properly maintained in SPSS version 21.

Hypertensive patients in the intervention group received a combination therapy for the management of hypertension which was based on DCP3 recommended strategies. Pharmacotherapy was provided by a physician and the intervention comprising of DCP3 interventions was administered by the researcher along with the physician in OPD. To control high blood pressure, at least two hypertensive medicines were prescribed by the physician in the treatment regimen which adhered to hypertension guidelines. Furthermore, patients were assessed at each visit for compliance to prescribed medications, lifestyle modification, stress management and changes in diet which included consumption of vegetables and a low fat food (85). The ultimate aim of the intervention was to reduce blood pressure among hypertensive patients and to improve patient's risk factors within recommended goals established in the intervention. Patients were given awareness about hypertension only at the initial point of the study after which patients who were randomized in intervention group were counseled and were prescribed multicomponent intervention at each consecutive visit in OPD department of hospital.

\section{Trial Outcomes}

The primary outcome of the study was to achieve an overall control rate and reduction in systolic blood pressure (SBP) to recommended level of $140 / 90 \mathrm{~mm} \mathrm{Hg}$ from baseline to three months after delivering the intervention in the intervention group. Adequate blood pressure control was assessed by taking blood pressure measurements of the patients in the intervention group and usual care group which was then compared to evaluate the effectiveness of the intervention.

\section{Statistical Analysis}


An average of blood pressure measurements was taken for each of the study participant at the baseline and follow up visits twice weekly at consecutive visits in the second and third month of enrollment of patients. Cleaning of the data was manually done prior to the analysis of the data in MS excel which was imported, coded and was entered in SPSS version 21 . The test for normality was applied using ShapiroWilks test with a $p$ value of $\leq 0.05$ whereas; reliability was calculated which was estimated using Cronbach's alpha ( $p$ value $\leq 0.58$ ). A minimal number of participants withdrew from the study (Figure 1 ) including those who were lost to follow up were excluded from the study inclusion and analysis. Descriptive statistics for sociodemographic variables were analyzed and reported in frequencies and percentages. To calculate the intervention effect, paired sample t-test was used with $95 \%$ confidence interval and $p$ value of less than 0.05 was considered as significant (Table 3 ).

\section{Results}

Nearly 240 hypertensive patients were enrolled and included in the trial in which 84 (70\%) make patients were randomized in the intervention group and 67 (55.8) were randomized in the usual care group. Including female hypertensive patients, 36 (30\%) were randomized in the intervention group and 53 (44.2\%) were randomized in the usual care group. As shown in Table 2, the results of research findings indicate that among all study participants $(\mathrm{N}=240)$, there were 46 patients of high blood pressure were of age less than 35 years and almost 194 patients were of age more than 35 years. Among these study participants, 143 were married in which 111 (92.5\%) were randomized in the intervention group and 107 $(89.2 \%)$ were randomized in the usual care group. Most of the hypertensive patients had an income of less than 50,000 Pakistani rupees. Among these 99 (51.8\%) were in the intervention group and 92 (48.2\%) were in the usual care group. A majority 159 hypertensive patients regularly sought medical care in which $39(24.5 \%)$ were in the intervention group and $120(75.4 \%)$ were in the usual care group. Out of 240 hypertensive patients that were included in the trial, 111 were health insured and 129 were non-insured. Most of the hypertensive patients had associated comorbidity of diabetes $(n=59)$ out of which $39(66.1 \%)$ were randomized in the intervention group and 20 (33.8\%) were randomized in the usual care group. Approximately, out of all hypertensive patients, $(n=45)$ had history of smoking. In the intervention group, $108(49 \%)$ were smoking for less than 10 years and $12(60 \%)$ has a smoking history of more than 10 years. Regarding positive familial history, 77 hypertensive patients answered to have a positive familial history of cardiac ailments and cardiovascular disease in which 26 (15.9\%) were randomized in the intervention group and 51 (31.2\%) were randomized in the usual care group. In Table 3, the mean systolic blood pressure of patients in the intervention group at baseline was estimated to be 148.99 .8 (mean SD) whereas, the mean systolic blood pressure of the patients was 150.39 .5 in the usual care group. After delivering the intervention, the estimated systolic blood pressure was 124.910 .4 in the intervention group and in usual care group it was 146.2 11.8. The intervention effect after three months of DCP3 intervention was calculated to be 13.9 (12.4 to 15.5) which was found to be significant ( $p$ value $\leq 0.05$ ). Similarly; the mean diastolic blood pressure of patients in the intervention group at baseline was estimated to be 94.49 .5 (mean SD) whereas, the mean diastolic blood pressure of the patients at the baseline was 98.87 .9 in the usual care group. After three months, the estimated diastolic blood pressure 
was 84.36 .5 in the intervention group and in usual care group it was 94.8 10.9. The intervention effect after three months of DCP3 intervention was calculated to be 10.1 (8.3 to 11.9) which was found to be significant ( $p$ value $\leq 0.05$ ). The mean change in systolic blood pressure of the intervention group was $-23.9 \pm 8.6$ was found to be positive whereas in the usual care group it was estimated to be $-4.02 \pm 4.4$. Similarly; the mean change in diastolic blood pressure of the intervention group was calculated to be $-10.2 \pm 10.2$ (mean \pm SD) also indicated in Figure 2 .

\section{Discussion}

The most common single risk factor for cardiovascular diseases is persistently high blood pressure. Incidence of hypertension is escalating in Pakistan with an estimated 18.9-29.2\% of Pakistani adults are reported to be hypertensive (11). According to a similar study conducted in Pakistan; almost $33 \%$ of individuals of age 45 years and above have hypertension (20). Gender diversification reveals that an estimated prevalence of hypertension among males in Pakistan is reported to be $24.9 \%$ and in females the prevalence is reported to be $24.7 \%$. $(18,19)$ Whereas; among adults (age above 18 years), one in four is reported to be hypertensive along with smoking in Pakistan (21). Consecutively, evidence also suggest that hypertension is more common among males than in females. $(10,22)$ Furthermore, in Pakistan, every third adult over the age of 40 years is predisposed to a wide range of diseases where; nearly $50 \%$ of patients are diagnosed with hypertension, consequently (23). Implementation of effective public health interventions that has been found effective in low and middle income countries including Pakistan such as population-based intervention on hypertensive patients (24). In addition, a national database or updated central registry for prevalence of hypertension is not available in Pakistan (25). Worldwide, hypertension is one of the most important cardiovascular risk factor (11) which prevails due to increased longevity as well as in the presence of contributing factors such as obesity, diabetes, salt intake, smoking, associated clinical conditions and other environmental risk factors.

This includes promotion of recommended interventions such as drug therapy, treating acute myocardial infarction (MI), acute ischemic stroke, managing diabetes and other co-morbidities (26). Whereas, preventive efforts including regular visits, blood pressure monitoring, better diet (such as DASH diet), smoke cessation, physical activity and life style modifications are generally found to be effective. Despite multiple causes of hypertension, the Framingham Heart Study showed a positive and independent association of risk of cardiovascular diseases with elevated blood pressure $(27,28)$. The total cardiac hemodynamic load comprising of sum of pulsatile load and steady-state load strongly determine the risk of coronary artery disease among hypertensive patients. Any single cause or combination of causes including internal and external factors overstates the incidence of hypertension and its related complications in an individual with high blood pressure. Therefore; identification of hypertensive patients is important so as to address the preventive aspect of complications among hypertensive patients (29).

A study was conducted in five countries including Pakistan to assess management of hypertension among 2185 patients in a clinical setting that focused on patient level factors. However; poor rates of BP 
control among patients was primarily linked to non-adherence to treatment, high salt intake and lack of understanding of importance of treatment along with co-morbidity (30). The results of study recommended promotion of guidelines and implementation of strategies to improve BP control rate. In this study a significant reduction was achieved in the mean systolic blood pressure of hypertensive patients enrolled in the intervention group as compared to usual care group in which hypertensive patients received routine medical care. The multi-component intervention was effective in reducing blood pressure, weight loss and lifestyle modification among hypertensive patients in the intervention group through counseling, use of regular medications, follow up and regular measurement and monitoring of blood pressure. In stage 2 hypertensive patients the use of blood pressure lowering agents among new diagnosed cases of hypertension was found to be effective. In many of the large scale randomized controlled trials, blood pressure has been greatly reduced by the effect of drugs which included antihypertensive therapies for the treatment of myocardial infarction and chronic heart failure (31). In some of the clinical trials, anti-hypertensive medications, demonstrated beneficial effects of blood pressure lowering agents in reducing the risk of stroke and coronary heart disease among hypertensive patients $(31,32)$.

However; in large-scale randomized controlled trials to evaluate the effectiveness of anti-hypertensive drugs, it was widely recognized and accepted that despite the efficacy of drugs in lowering blood pressure and cardiovascular risk and events, the management of hypertensive concerning other elements apart of medications alone have direct effect on the progression of high blood pressure to cardiovascular related diseases. The target with anti-hypertensive drugs could be with the drug treatment to lower blood pressure to the recommended target for which treatment is actually initiated among hypertensive patients. But the influence of medications along with cardiovascular risk factors to which an individual group from high risk could be susceptible is more important. Therefore, considering the total cardiovascular risk earlier among high risk individuals with high blood pressure is significantly essential for aggressive treatment initiation and control of risk factors amenable to cardiovascular events.

Among hypertensive patients in the intervention group, those who had positive family history of high blood pressure and cardiovascular diseases, adhered more to the multi-component intervention based on DCP3 strategies for hypertension management and control. Most of the male and female hypertensive patients visited public sector hospitals for their treatment and diagnosis of cause of sign and symptoms of headache, chest tightness, chest pain and shortness of breath. In this regard, it is valuable to promote patient education and among general population about high blood pressure and its related complications. The awareness for hypertension and cardiovascular diseases should be raised among individuals from high risk groups and patients with positive familial history at the community level, primary, secondary and tertiary healthcare levels in the country. Among these $58.2 \%$ (128) patients in this study had no formal education or had less than $<10$ years of education who largely depended on the counseling and more time provided by the physicians for prevention against cardiovascular diseases. Similarly; at the baseline of the trial, $40.8 \%$ (49) of the patients who were current smoker for more than 15 years and those who were smoking less than 15 years i.e. 7.5\% (09) showed a significant decrease in smoking at the end of trial. These patients encouraged importance of early detection of hypertension to 
be raised by education in masses by doctors, awareness campaigns, media, lady health workers in the community and dissemination of information through seminars and conferences. In addition, among currently diagnosed hypertensive patients which included $45.8 \%$ (55) male hypertensive patients and $57.1 \%$ (20) female hypertensive patients who reported suffering from diabetes mellitus as per their medical record were unaware of high blood pressure which were screened upon enrollment in the study. This necessitates emphasis on promotion of health regarding hypertension by pharmacists and trained healthcare workers working in the local areas or communities which can greatly serve the purpose of task-shifting $(33,34)$.

It is essential for hypertension management and control that early detection may be done with early initiation of hypertension treatment to reduce incidence of related complications $(35,36)$. The findings of study reveals that a disease control priorities (DCP3) based strategies was effective in BP control and control of hypertension and its management. The multi-component intervention based on DCP3 strategies for hypertension management and control was found beneficial and effective in reducing blood pressure of hypertensive patients during three months. Lifestyle modifications such as low intake of salt, regular exercise, adherence to prescribed medicines require patient centered approach. Counseling related to non-pharmacological or behavioural counseling for lifestyle changes consume a less amount of time for hypertensive patients. However; from the perspective of preventive cardiology, on an average a patient requires more time and detailed information for counseling primarily by the physician on every aspects of medicine intake, depression, stress and preventive measures for high blood pressure.

\section{Conclusion}

The study findings conclude that early prevention and detection of hypertension is an effective population level strategy that should be implemented at household, rural, secondary and tertiary healthcare levels. Rehabilitative counseling regarding prevention from complications of high blood pressure and cardiovascular diseases (CVDs) are intensively required at a tertiary level hospital.

\section{Abbreviations}

AFIC Armed Forces Institute of Cardiology

BHU Basic health units

BMI Body mass index

CNIC Computerized National Identity Card

CVD Cardiovascular disease

DASH Dietary approaches to stop hypertension

DCP Disease Control Priorities 
ICD International Classification of Diseases

LMICs Low and middle income countries

NCD Non-Communicable Diseases

OPD Out-patient department

SBP Systolic blood pressure

SD Standard deviation

WHO World Health Organization

\section{Declarations}

\section{Availabity of data and materials}

The datasets supporting the conclusions of this article is available in the Randomized Controlled Trial Study on Hypertension can be accessed from DOI 10.17605/OSF.IO/N56AD.

\section{Authors Contribution}

SA conceived the research idea and contributed to development of materials, data collection writing and editing of the manuscript. AH, SAK and AZ supervised and reviewed the study. All authors approved the final manuscript.

\section{Acknowledgements}

The authors would like to thank Dr. Assad Hafeez for supervising this study and providing valuable isnights in improvising the manuscript.

\section{Competing interest}

All authors declare no conflict of interest.

\section{Declaration Section}

\section{Consent for Publication}

I hereby give my consent to publish my original research paper. Institutional approval to conduct this study was taken from Health Services Academy Islamabad vide letter no. 01-07/2017/PhD dated: 8th November, 2019.

\section{Ethics Approval and Consent to Participate}


The study was carried out in accordance to research protocol and guidelines developed to conduct this study which involved human subjects. The ethics approval was sought from Health Services Academy Islamabad vide letter no. 01-07/2017/PhD dated: 8th November, 2019.

\section{Funding statement}

No funding was received.

\section{References}

1. High Blood Pressure | National Heart, Lung, and Blood Institute (NHLBI). [cited 2019 Oct 12]. Available from: https://www.nhlbi.nih.gov/health-topics/high-blood-pressure

2. Hypertension. [cited 2019 Oct 12]. Available from: https://www.who.int/news-room/factsheets/detail/hypertension

3. WHO | Hypertension. WHO. 2017 [cited 2018 Dec 30]; Available from: https://www.who.int/topics/hypertension/en/

4. ICD-11. [cited 2019 Oct 12]. Available from: https://icd.who.int/dev11/f/en\#/http\%3A\%2F\%2Fid.who.int\%2Ficd\%2Fentity\%2F924915526

5. Hypertension: pathophysiology and treatment. [cited 2019 Oct 13]; Available from: https://watermark.silverchair.com/mkh020.pdf

6. WHO | Raised blood pressure. WHO. 2015 [cited 2019 Jan 11]; Available from: https://www.who.int/gho/ncd/risk_factors/blood_pressure_prevalence_text/en/

7. Bozkurt B, Aguilar D, Deswal A, Dunbar SB, Francis GS, Horwich T, et al. Contributory Risk and Management of Comorbidities of Hypertension, Obesity, Diabetes Mellitus, Hyperlipidemia, and Metabolic Syndrome in Chronic Heart Failure: A Scientific Statement from the American Heart Association. Vol. 134, Circulation. Lippincott Williams and Wilkins; 2016 [cited 2020 Feb 27]. p. e535-78. Available from: https://www.ahajournals.org/doi/10.1161/CIR.0000000000000450

8. Khan SA. Hypertension: A sufficient risk factor for cardiovascular diseases. [cited $2021 \mathrm{Jul} 16$ ]. Available from: https://www.pafmj.org/index.php/PAFMJ/article/view/4021/3433

9. Ishtiaq S, llyas U, Naz S, Altaf R, Afzaal H, Muhammad SA, et al. Assessment of the risk factors of hypertension among adult \& elderly group in twin cities of Pakistan. Vol. 67. 2017.

10. Everett B, Zajacova A. Gender Differences in Hypertension and Hypertension Awareness Among Young Adults. Biodemography Soc Biol. 2015 [cited 2019 Jul 27];61(1):1. Available from: https://www.ncbi.nlm.nih.gov/pmc/articles/PMC4896734/

11. WHO | A global brief on hypertension. WHO. 2013 [cited 2018 Dec 31]; Available from: https://www.who.int/cardiovascular_diseases/publications/global_brief_hypertension/en/

12. Consort - Welcome to the CONSORT Website. [cited 2019 Jul 15]. Available from: http://www.consortstatement.org/ 
13. ICD-10 Version:2016. [cited 2020 Mar 11]. Available from: https://icd.who.int/browse10/2016/en\#/I10-115

14. David H Peters. Implementation research: what it is and how to do it. [cited 2020 Sep 7]; Available from: https://www.bmj.com/content/bmj/347/bmj.f6753.full.pdf

15. AFIC / NIHD. [cited 2019 Jul 14]. Available from: http://afic.gov.pk/?page_id=126

16. Akber S. Perception and practices of healthcare providers and hypertensive patients for accessing treatment of hypertension at a tertiary level hospital in rawalpindi, pakistan: a study protocol. [cited 2020 Mar 19]. Available from: https://www.pafmj.org/index.php/PAFMJ/article/view/3932/2548

17. Brokmann JC, Rossaint R, Müller M, Fitzner C, Villa L, Beckers SK, et al. Blood pressure management and guideline adherence in hypertensive emergencies and urgencies: A comparison between telemedically supported and conventional out-of-hospital care. J Clin Hypertens. 2017 Jul [cited 2019 Jul 31];19(7):704-12. Available from: http://www.ncbi.nlm.nih.gov/pubmed/28560799

18. Shah N, Shah Q, Shah AJ. The burden and high prevalence of hypertension in Pakistani adolescents: a meta-analysis of the published studies. [cited 2019 Jan 11]; Available from: https://doi.org/10.1186/s13690-018-0265-5

19. Ishtiaq S, llyas U, Naz S, Altaf R, Afzaal H, Muhammad SA, et al. Assessment of the risk factors of hypertension among adult \&amp; elderly group in twin cities of Pakistan [Internet]. Vol. 67. 2017 [cited 2019 Jul 27]. Available from: https://jpma.org.pk/PdfDownload/8428

20. Tazeen Jafar. AKU Launches Largest Study on Hypertension in Pakistan I The Aga Khan University News. [cited 2019 Jul 28]. Available from: https://clinicaltrials.gov/ct2/show/record/NCT00327574

21. Health situation. 2018 [cited 2019 Jul 20]. Available from: http://apps.who.int/gho/data/node.cco

22. Singh S, Shankar R, Singh GP. Prevalence and Associated Risk Factors of Hypertension: A CrossSectional Study in Urban Varanasi. Int J Hypertens. 2017 [cited 2019 Jul 27];2017:5491838. Available from: http://www.ncbi.nlm.nih.gov/pubmed/29348933

23. Saleem F, Dua JS, Hassali AA, Shafie AA. Hypertension in Pakistan: time to take some serious action. Br J Gen Pract. 2010 Jun [cited 2019 Jul 27];60(575):449-50. Available from: http://www.ncbi.nlm.nih.gov/pubmed/20529498

24. Afshin A, Micha R, Webb M, Capewell S, Whitsel L, Rubinstein A, et al. Effectiveness of Dietary Policies to Reduce Noncommunicable Diseases. [cited 2019 Jan 11]. Available from: http://dcp3.org/sites/default/files/chapters/DCP3 CVRD_Ch 6.pdf

25. Saqlain M, Riaz A, Naeem Malik M, Khan S, Ahmed A, Kamran S, et al. medicina Medication Adherence and Its Association with Health Literacy and Performance in Activities of Daily Livings among Elderly Hypertensive Patients in Islamabad, Pakistan. 2019 [cited 2020 Mar 3]; Available from: www.mdpi.com/journal/medicina

26. Best Buys. Tackling NCDs. 2009 [cited 2019 Jan 12]. Available from: http://apps.who.int/iris/bitstream/handle/10665/259232/WHO-NMH-NVI-17.9-eng.pdf?sequence=1

27. Ageing series. Blood pressure and ageing. Postgr Med J. 2007 [cited 2020 Mar 3];83:109-14. Available from: www.postgradmedj.com 
28. Ageing and Hypertension: The Assessment of Blood Pressure Indices in Predicting Coronary Heart Disease - PubMed. [cited 2020 Mar 3]. Available from: https://pubmed.ncbi.nlm.nih.gov/10706323ageing-and-hypertension-the-assessment-of-blood-pressure-indices-in-predicting-coronary-heartdisease/

29. Suvila K, McCabe EL, Lehtonen A, Ebinger JE, Lima JAC, Cheng S, et al. Early Onset Hypertension Is Associated With Hypertensive End-Organ Damage Already by MidLife. Hypertens (Dallas, Tex 1979). 2019 Jul 1 [cited 2020 Mar 3];74(2):HYPERTENSIONAHA11913069. Available from: http://www.ncbi.nlm.nih.gov/pubmed/31256722

30. Ragot S, Beneteau M, Guillou-Bonnici F, Herpin D. Prevalence and management of hypertensive patients in clinical practice: Cross-sectional registry in five countries outside the European Union. Blood Press. 2016 Mar 3 [cited 2019 Jul 31];25(2):104-16. Available from: http://www.ncbi.nlm.nih.gov/pubmed/26873621

31. Zanchetti A, Thomopoulos C, Parati G. Randomized Controlled Trials of Blood Pressure Lowering in Hypertension. Circ Res. 2015 Mar 13 [cited 2020 Apr 10];116(6):1058-73. Available from: https://www.ahajournals.org/doi/10.1161/CIRCRESAHA.116.303641

32. Chakraborty BS. Clinical trials of antihypertensives: Nature of control and design. Indian $\mathrm{J}$ Pharmacol. 2011 Feb;43(1):13-7.

33. Victor RG, Lynch K, Li N, Blyler C, Muhammad E, Handler J, et al. A Cluster-Randomized Trial of BloodPressure Reduction in Black Barbershops. N Engl J Med. 2018 Apr 5 [cited 2018 Dec 30];378(14):1291-301. Available from: http://www.nejm.org/doi/10.1056/NEJMoa1717250

34. Jafar TH, Hatcher J, Poulter N, Islam M, Hashmi S, Qadri Z, et al. Community-Based Interventions to Promote Blood Pressure Control in a Developing Country. Ann Intern Med. 2009 Nov 3;151(9):593.

35. Lippincott Williams \& Wilkins. 2003 World Health Organization (WHO)/International Society of Hypertension (ISH) statement on management of hypertension. [cited 2019 Jan 11]; Available from: https://www.who.int/cardiovascular_diseases/guidelines/hypertension_guidelines.pdf?ua=1

36. WHO | WHO/ISH Hypertension guidelines. WHO. 2013 [cited 2019 Jan 11]; Available from: https://www.who.int/cardiovascular_diseases/guidelines/hypertension/en/

\section{Tables}


Table 1

Interventions for Primary Prevention of Cardiovascular Diseases Based Upon Disease Control Priorities 3rd Edition (Adapted)(17)

STRATEGIES FOR MANAGEMENT \& CONTROL OF HYPERTENSION

A) Modifications of Risk factors through Life Style Changes

1. Cessation of Smoking Smoking Cessation, Weight Loss

2. Exercise/Physical

Activity

3. Dietary Modification Reduction in Salt Intake/Alcohol, DASH diet

B) Pharmacological Treatments/Detection of High Risk/Management

1. Elevated Blood Pressure Regular visits \& follow up. Recommended $B P<140 / 90 \mathrm{~mm} \mathrm{Hg}$

2. Hypercholesterolemia

3. Dyslipidemia

4. Diabetes

C) Non-Pharmacological

1. Behavioral Counseling Awareness, lifestyle modification and changes in diet and pattern 
Table 2

Demographic Characteristics of Hypertensive Patients at a Tertiary Level Hospital in Rawalpindi, Pakistan $(\mathrm{N}=240)$

\begin{tabular}{|c|c|c|c|}
\hline \multicolumn{2}{|l|}{ Characteristics of Study Participants } & $\begin{array}{l}\text { Intervention } \\
\text { Group } \\
\mathrm{N}(\%)\end{array}$ & $\begin{array}{l}\text { Usual Care } \\
\text { Group } \\
\text { N (\%) }\end{array}$ \\
\hline \multirow{2}{*}{$\begin{array}{l}\text { Age in years } \\
(51.9 \pm 14.6)\end{array}$} & $\begin{array}{l}\text { Less than } 35 \\
\text { years }\end{array}$ & $25(20.8)$ & $21(17.5)$ \\
\hline & $\begin{array}{l}\text { More than } 35 \\
\text { years }\end{array}$ & $95(79.2)$ & $99(82.5)$ \\
\hline Married & $n=143$ & $111(92.5)$ & $107(89.2)$ \\
\hline \multirow{2}{*}{$\begin{array}{l}\text { Education } \\
\text { (in years) }\end{array}$} & Below 10 years & $84(48.5)$ & $89(51.4)$ \\
\hline & Above 10 years & $36(53.7)$ & $31(46.3)$ \\
\hline Annual Income & $\leq 50,000$ & $99(51.8)$ & $92(48.2)$ \\
\hline \multirow[t]{2}{*}{ In PKR } & $\geq 50,000$ & $21(42.8)$ & $28(57.1)$ \\
\hline & Other & $36(46.7)$ & $41(53.2)$ \\
\hline \multirow[t]{2}{*}{ Regular Medical Care } & Yes $(n=159)$ & $39(24.5)$ & $120(75.4)$ \\
\hline & No $(n=81)$ & $120(0)$ & $39(32.5)$ \\
\hline \multirow[t]{2}{*}{ Health Insurance } & Yes $(n=111)$ & $39(35.1)$ & $72(64.8)$ \\
\hline & No $(n=129)$ & $81(62.7)$ & $48(37.2)$ \\
\hline \multirow[t]{3}{*}{ Risk Factors } & Smoking $(n=45)$ & $35(77.7)$ & $10(22.2)$ \\
\hline & Diabetes $(n=59)$ & $39(66.1)$ & $20(33.8)$ \\
\hline & $\mathrm{BMI}>(\mathrm{n}=22)$ & $06(2.6)$ & $16(6.9)$ \\
\hline \multirow[t]{2}{*}{ Smoking } & $\begin{array}{l}\text { Less than } 10 \\
\text { years }\end{array}$ & $108(49.0)$ & $112(5.0)$ \\
\hline & $\begin{array}{l}\text { More than } 10 \\
\text { years }\end{array}$ & $12(60.0)$ & $08(40.0)$ \\
\hline $\begin{array}{l}\text { Positive Family History for CHD or } \\
\text { CVD }\end{array}$ & $n=77$ & $26(15.9)$ & $51(31.2)$ \\
\hline
\end{tabular}


Table 3

Blood Pressure Outcomes in the Intervention and Control Group of the Hypertension Trial at a Tertiary Level Hospital in Rawalpindi Pakistan $(\mathrm{N}=240)$

\begin{tabular}{|c|c|c|c|c|}
\hline \multirow[t]{2}{*}{ Blood Pressure Outcomes } & $\begin{array}{l}\text { Intervention } \\
\text { Group }\end{array}$ & $\begin{array}{l}\text { Usual Care } \\
\text { Group }\end{array}$ & $\begin{array}{l}\text { Intervention } \\
\text { Effect }\end{array}$ & $\begin{array}{l}P \\
\text { value }\end{array}$ \\
\hline & $N=120$ & $N=120$ & & \\
\hline BP in mm Hg Male & $84(70)$ & $67(55.8)$ & & \\
\hline Female & $36(30)$ & $53(44.2)$ & & \\
\hline Systolic BP At Baseline & $148.9 \pm 9.8$ & $150.3 \pm 9.5$ & & \\
\hline At 3 months & $124.9 \pm 10.4$ & $146.2 \pm 11.8$ & $\begin{array}{l}13.9(12.4 \text { to } \\
15.5)\end{array}$ & $\leq 0.05$ \\
\hline Change in Blood Pressure & $-23.9 \pm 8.6$ & $-4.02 \pm 4.4$ & & \\
\hline Diastolic BP At Baseline & $94.4 \pm 9.5$ & $98.8 \pm 7.9$ & & \\
\hline At 3 months & $84.3 \pm 6.5$ & $94.8 \pm 10.9$ & $\begin{array}{l}10.1(8.3 \text { to } \\
11.9)\end{array}$ & $\leq 0.05$ \\
\hline Change in Blood Pressure & $-10.2 \pm 10.2$ & $0.0 \pm 0.0$ & & \\
\hline \multicolumn{5}{|l|}{$\begin{array}{l}\text { Hypertension Control at } 3 \\
\text { months }\end{array}$} \\
\hline $\mathrm{BP}<140 / 90 \mathrm{~mm} \mathrm{Hg}$ & $40(16.7)$ & $120(100)$ & 1.4 (1.3 to 2.7$)$ & $\leq 0.05$ \\
\hline $\mathrm{BP}<130 / 80 \mathrm{~mm} \mathrm{Hg}$ & $62(25.8)$ & $0(0)$ & 2.4 (1.3 to 9.1$)$ & $\leq 0.05$ \\
\hline $\mathrm{BP}<120 / 80 \mathrm{~mm} \mathrm{Hg}$ & $18(7.5)$ & $0(0)$ & 2.8 (2.3 to 11.5$)$ & $\leq 0.05$ \\
\hline
\end{tabular}

Figures 

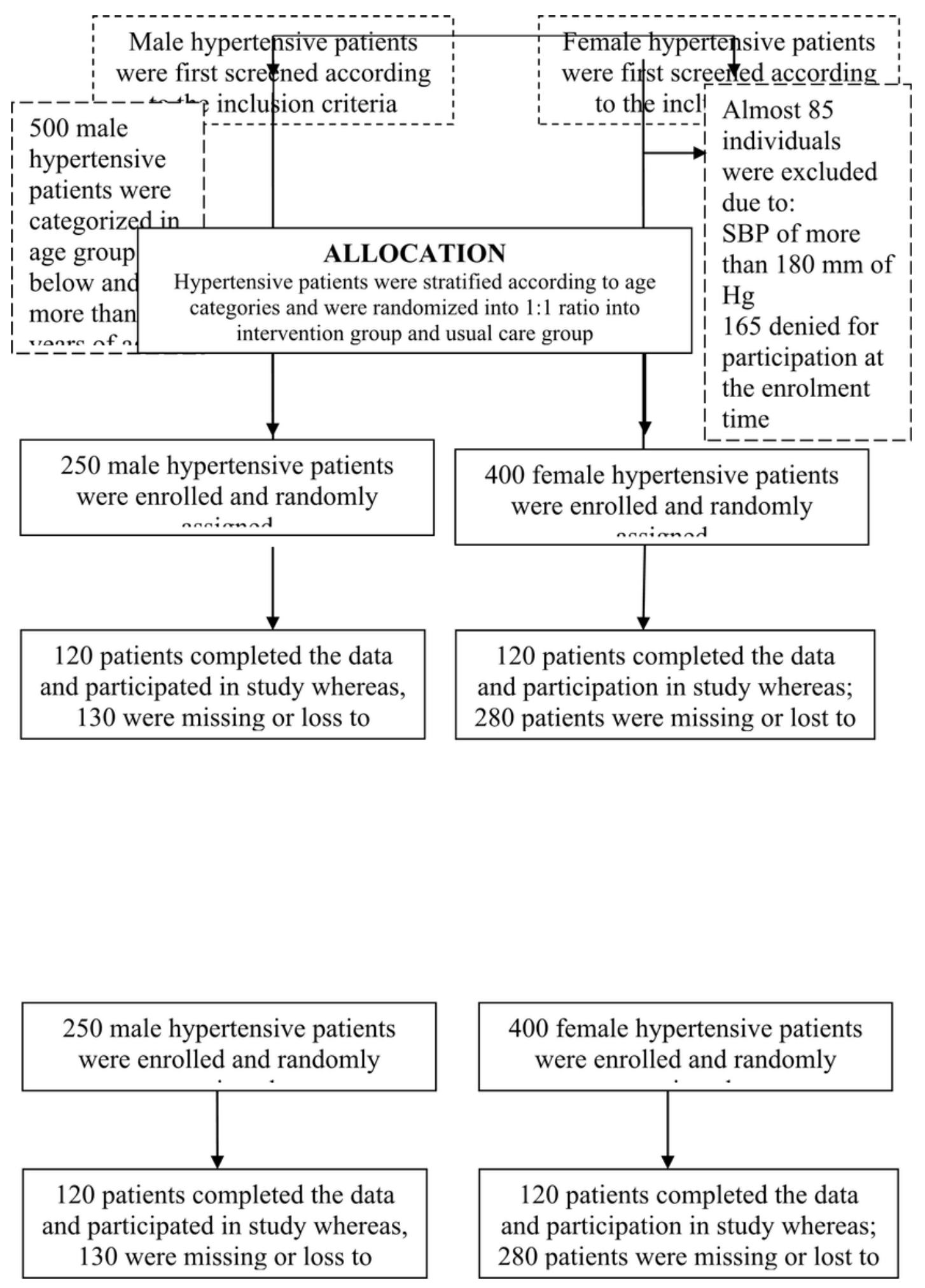

\section{Figure 1}

Overall Screening, Enrollment and Follow Up of Hypertensive Patients at a Tertiary Hospital in Rawalpindi, Pakistan according to CONSORT Guidelines. 


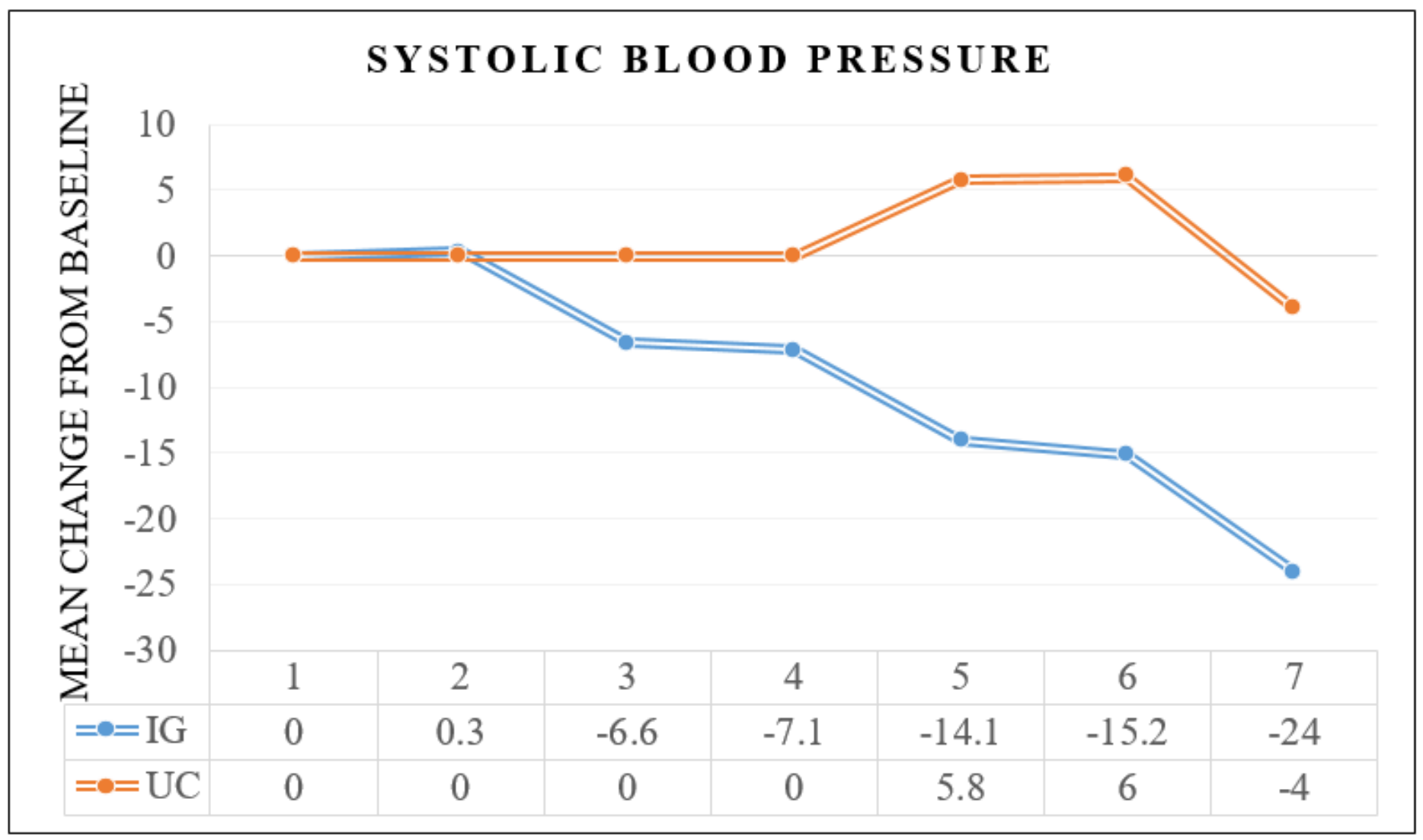

Figure 2

Mean Change in Systolic Blood Pressure of Enrolled Hypertensive Patients in the Intervention Arm $(\mathrm{N}=120)$

\section{Supplementary Files}

This is a list of supplementary files associated with this preprint. Click to download.

- CONSORT2010Checklist.doc 